\title{
Reanimating archaeology:
}

\section{Review of Kristin Armstrong Oma's The Sheep People: The Ontology of Making Lives, Building Homes and Forging Herds in Early Bronze Age Norway}

Kristin Armstrong Oma has written an ambitious, thoughtful and important book. Let there be no doubt; the endeavour she sets out on is a complicated one - one that involves many different fields of enquiry with rather disparate origins and priorities that do not necessarily match easily. For this reason, the reader will find a substantial number of different agendas in Oma's book, which are all relevant but not equally central to what I take to be the book's main aim: to strengthen and reconfigure archaeological thought on the coexistence of humans and non-human animals in past societies, in particular in contexts of farming. While theoretical attention to the relationship between humans and animals in the past has often framed domestication as a shift towards an asymmetrical relation in which humans simply exploit other species (e.g. Ingold 2000), Oma's ambition is a much more sophisticated and profound one. Centring her discussions around the coexistence of humans, sheep and sheep dogs in Bronze Age Rogaland, western Norway, she works carefully to elucidate not only economic rationales but also the strong aspects of interdependency, reciprocity and companionship that often emerge when humans and domestic animals live closely together, as they have predominately done until the advent of modern factory farming.

In Chapter 1, Oma presents her project as a "multispecies "archaeology of life" (p. 3) and situates her work within the emerging field of archaeology informed by Human-Animal Studies, and in contrast to traditional zooarchaeology. She then outlines the book's two main objectives; first, 'a theoretical exploration of human-farm animal interactions', and second, an investigation of the transition from two-aisled to three-aisled houses in Rogaland and its potential connection to new forms of human-animal coexistence (p. 3). Oma also discusses the epistemological challenge of understanding relationships between humans and animals in the past, suggesting that 'Often it is easier to see the wood for the trees from a distance, and as such easier to unpick the way animals were perceived and related to in societies that are not our own' (p. 6). While this sentence does not reflect the full nuance of Oma's position here and while I am sympathetic to its entrepreneurial spirit as general outlook (and see no good alternative), some might find this twist on the challenge faced a little too convenient.

Kontakt: Niels N. Johannsen, E-post: nnj@cas.au.dk

Institut for Kultur og Samfund, Aarhus Universitet 
Chapters 2 and 3 are devoted to developing a deeper archaeological understanding of animals as sentient beings and agents, which has monumental implications for how we perceive daily life in traditional farming communities. The work done by Oma in these two chapters, including her productive discussion of the tension between the necessities and biases of anthropomorphism, is quite simply important for our perspectives on most of the societies we study, and I believe that reading them would be an eye-opener to most archaeologists. And I say this despite the fact that to me, these two chapters also seemed the least resolved part of the book - which is not surprising given the vast intellectual ground that Oma straddles here; findings and theories made in social anthropology, ethology, actornetwork theory, neuroscience, feminist and post-humanist studies and biochemistry are sprinkled with interesting observations made by people who work professionally together with animals on a daily basis. I wondered whether a more elaborated focus on biological and cognitive-behavioural science studies looking at cross-species continuities and the detailed dynamics of human-animal interaction, traded perhaps for a more selective summary of work debating metaphysical and political aspects of ontology/ontological thinking, might have allowed Oma to establish her important conclusions concerning the interaction, contact and connections between humans and non-human animals with even greater clarity?

In Chapter 4, Oma considers the archaeological evidence on developments in architecture, household and farm life in Bronze Age Rogaland. The author creates a useful, easily accessible overview of this material, including extensively investigated, key settlement sites like Forsandmoen, Kvåle and Tjora, and situates the settlements and their patterning in the similarly well-investigated palaeoenvironmental context of the region. In this chapter, the supplement of house ground plans with two 'artist's impression' drawings that assist the reader in considering Bronze Age life in two- and three-aisled houses, respectively, exemplifies the competent selection of illustrations for this book. While each of the available lines evidence drawn together, not least the very scant faunal remains, is surely less plentiful than the author might wish for, in combination they are sufficient to render plausible the author's suggestion that the shift from two- to three-aisled houses marks the beginning of a closer cohabitation of humans and sheep, in which the sheep (or some of them) were taken into the household for parts of the year.

Chapter 5 maps the evidence for sheep and dogs across Bronze Age Scandinavia and provides a thorough, insightful analysis of the multispecies dynamics of (sheep) herding. By considering modern herding cooperative dynamics, Oma establishes a strong comparative basis for understanding what this type of activity and way of life entailed in a prehistoric context. Not surprisingly, the triadic interaction of sheep, sheep dog and shepherd lends itself particularly well to Oma's emphasis of 'stakeholder' companionship. I especially enjoyed this chapter, and I learnt a lot reading it.

Oma concludes her book with the chapter 'The Sheep People: Towards An Archaeology of Ontology' (Chapter 6). I am not entirely sure that the last part of that title indicates what is actually the main deliverable provided by Oma's book - at least, it seems too unspecific to do justice to her synthesis. The chapter brings together the Bronze Age regional case study with the theoretical considerations presented in the first third of the book, along with various modern-day observations. Drawing parallels to present-day situations, Oma argues that human-sheep cohabitation, including the very significant, early establishment of relations of care between humans and sheep (lambs), would have brought with it a number of 
advantages predicated on some level of trust between species. Central among these is how a relatively close relationship allows for an efficient yet gentle retrieval of wool from the sheep, which was a resource that played a rather important cultural role in Bronze Age Scandinavia. With this concluding chapter, Oma shows how a close attention to humananimal relationships can inform and enrich our understanding of past societies at many different levels, and in so doing she amply demonstrates the viability of the agenda laid out early in the book.

The Sheep People is for the most part a well-written and carefully laid out book. Here and there, though, I would have liked to see more careful referencing of claims and positions in the cited literature, e.g. on p. 9, when a specific argument by Ian Hodder (concerning the uneasy theoretical status of past human thought in classical processual archaeology) is simply ascribed to his 1992 book Theory and Practice in Archaeology. Conversely, Oma sometimes seems overly keen to weave in catchy phrases and punchlines that she came across in the extensive theoretical literature that she covers - for example on p. 131, where she refers to H. Buller stating that animals (as autonomous, animate agents) 'flirt between the worlds of lost and found'. While this has a ring to it, I (not having read Buller) had no clear idea what the intended meaning or contribution of this phrase was. For me at least, this and a not insignificant number of similar, discursive adornments did not improve the clarity, nuance or substance of Oma's consideration, and indeed did not need to. But these are both minor quibbles - overall, the book is well crafted and accessible, despite its inherent thematic complexity.

By the end of Oma's book, my feeling was that I had been presented with something original - something that I might, for lack of more eloquent words, call a socioenvironmentally grounded, affective-cognitive archaeology with a developed multispecies focus and sensitivity. Yes, as indicated above, this is as complicated as it sounds. It seemed to me half developed and half nascent, and I mean that in a positive sense primarily. With its thrust to introduce a more competent attention to and understanding of non-human animals and our lives with them, Oma's contribution provides a much-needed counterbalance to our more developed and coveted interest in the affective, cognitive and social roles and effects of inanimate things and structures. Despite archaeology's empirical starting point in material culture, it seems more than a little ironic that archaeologists should bypass non-human animals and turn directly to inanimate things when they started considering that non-humans might be important agents too (e.g. Olsen 2003). My guess is that Oma's book will be a landmark in one of several important, new agendas for theoretical and empirical enquiry in 21 st century archaeology. And, perhaps, a little more respect for life in the discipline of things might not be a bad thing. 


\section{References}

Ingold, Tim

2000 From trust to domination: An alternative history of human-animal relations. In The Perception of the Environment: Essays in Livelihood, Dwelling and Skill, edited by T. Ingold, pp. 61-67.

Routledge, London.

Olsen, Bjørnar

2003 Material Culture after Text: Re-Membering Things'. Norwegian Archaeological Review 36(2), $87-104$. 